\title{
Physiotherapy on the Complications of Head and Neck Cancer: Retrospective Study
}

\author{
${ }^{1}$ Rogerio Eduardo Tacani, ${ }^{2}$ Aline Fernanda Perez Machado, ${ }^{3}$ João Carlos G Sampaio Goes, ${ }^{4}$ Angela Gonçalvez Marx \\ ${ }^{5}$ Juliana Pereira Franceschini, ${ }^{6}$ Pascale Mutti Tacani
}

\begin{abstract}
Introduction: Physiotherapy has an important role in cancer rehabilitation, particularly with the head and neck cancer patients, in an attempt to minimize the morbidities caused by the disease and its treatment.

Objective: To determine the role of physiotherapy treatment in morbidities of head and neck cancer, in a retrospective investigation, at one oncologic hospital.
\end{abstract}

Materials and methods: Retrospective study based on the analysis of medical records of 32 patients treated at the Outpatient Physiotherapy Department at the Brazilian Institute of Cancer Control (IBCC), from August 2008 to July 2010.

Results: Twenty-nine medical records were evaluated, $86.2 \%$ were males with cancer in the oral cavity $(41.4 \%)$ that had radical neck dissection (69\%) and radiotherapy (86.2\%), evolving with lymphedema (89.7\%), pain (82.8\%), normotrophic scar $(65.5 \%)$, tissue adherence $(27.6 \%)$ and hypoesthesia $(51.7 \%)$. The physiotherapeutic treatment included: manual lymphatic drainage $(89.7 \%)$, transcutaneous electrical nerve stimulation (TENS; 51.7\%), mechanical massage therapy (37.9\%), stretching exercises $(79.3 \%)$ and patient education (100\%). The results showed a reduction of pain and lymphedema, increased normotrophic scars and normoesthesia, with an average of $19.3 \pm$ 14.5 sessions and treatment discharge of $65.5 \%$.

Conclusion: Physical therapy in morbidities of head and neck cancer was effective in reducing pain and lymphedema, combining manual lymphatic drainage, transcutaneous electrical nerve stimulation (TENS), mechanical massage therapy, stretching exercises and patient education, with an average of 19 sessions and discharge after treatment.

Keywords: Head and neck cancer, Pain, Physical therapy modalities, Muscle stretching exercises, Rehabilitation, Lymphedema.

\footnotetext{
1,2,4-6Professor, ${ }^{3} \mathrm{Head}$

${ }^{1}$ Department of Physical Therapy, Sao Camilo University Centre, São Paulo, Brazil

${ }^{2}$ Department of Physical Therapy, Paulista University, São Paulo, Brazil

${ }^{3}$ Department of Medicine, Brazilian Institute of Cancer Control São Paulo, Brazil

${ }^{4}$ Department of Physical Therapy, Faculty of Health Sciences (FACIS), São Paulo, Brazil

${ }^{5,6}$ Department of Physical Therapy, Brazilian Institute of Cancer Control, São Paulo, Brazil
}

Corresponding Author: Pascale Mutti Tacani, Professor Department of Physical Therapy, Brazilian Institute of Cancer Control, São Paulo, Brazil, Phone: 551134744222 e-mail: pascale.tacani@hotmail.com
How to cite this article: Tacani RE, Machado AFP, Goes JCGS, Marx AG, Franceschini JP, Tacani PM. Physiotherapy on the Complications of Head and Neck Cancer: Retrospective Study. Int J Head Neck Surg 2014;5(3):112-118.

Source of support: Nil

Conflict of interest: None

\section{INTRODUCTION}

Physiotherapy treatment in oncology patients is continuously evolving, as one of health professional transdisciplinary team, since that cancer treatments have increased the survival rate for many patients, ${ }^{1}$ which is estimated in approximately $57 \%$ in 5 years for head and neck tumors. ${ }^{2}$

Treatment for head and neck cancer involves surgery, radio and chemotherapy. The more advanced the stage of the disease, the broader the resection, and more complex the reconstruction, leading to significant morbidities. ${ }^{2-5}$ The sequelae of the disease or the clinical treatment interferes with the patients' quality of life $\mathrm{e}^{1,2,6}$ forcing them to undergo some complex rehabilitation programs. ${ }^{7,8}$

The acute post-treatment morbidities, especially due to radiation, causes oral mucositis, radiodermatitis, pain, thickening and increased viscosity of mucus production, xerostomia, soft-tissue edema, and infection of the surgical wound, making swallowing and other functions very difficult. ${ }^{4,5,8}$

The late post-treatment morbidities that start 3 months after the cancer treatment completion can cause xerostomia, dysphasia and lymphedema $a^{8-11}$ as well as fibrosis and tissue stiffness. ${ }^{8,10}$

There may be also, nerve damage, resulting in functional deficits, such as facial paralysis, pain, muscle weakness and reduced range of motion (ROM) of the neck and shoulder (accessory nerve shoulder dysfunction), trismus and ankylosis of temporomandibular joint. ${ }^{4,7,9,12}$

Physiotherapy aims to prevent and/or minimize the multiple complications ${ }^{1,7}$ by using some modalities to help on the viability of grafts and flaps, wound care and its healing evolution, ${ }^{13}$ signs and symptoms related to acute and chronic inflammatory process, such as pain, edema and fibrosis, respiratory capacity, recovery of the movements of the face, neck, upper limb girdle and body posture, and the neurological functions related to sensitivity and locomotion. This way, it can help these patients restore their physical, emotional, social and labor capacity. ${ }^{1,7,12,14}$ 
At this moment, there is insufficient scientific evidence to demonstrate the effectiveness of physiotherapy in the rehabilitation of postoperative complications of patients with head and neck cancer, ${ }^{15}$ in addition to the lack of descriptions regarding the resources, modalities, number of therapies and further information that can be used to minimize the major sequelae. Therefore, this study aimed to determine the role of physiotherapy treatment in morbidities of head and neck cancer, in a retrospective investigation, at one oncologic hospital.

\section{MATERIALS AND METHODS}

A retrospective study based on the analysis of medical records of 32 patients treated in the Physiotherapy Department as Outpatient of the Brazilian Institute of Cancer Control (IBCC) from August 2008 to July 2010 and it was approved by the Ethics Committee of the Institute. The following informations were collected: date of birth, age, gender, medical diagnosis, time evolution of disease, medical treatment, physiotherapeutic diagnosis, physical examination, physical therapy modalities, number of sessions and treatment outcome. In the physical examination, the presence of pain was classified using visual analog scale (VAS) the type of scar by inspection and palpation, sensitivity by Semmes-Weinstein monofilaments test, and lymphedema by inspection, palpation, classification and standard measurements according to Tacani et al (2010), ${ }^{16}$ which were described in the medical records. The lymphedema classification was based on Consensus Document of the International Society of Lymphology ${ }^{17}$ staging system: stage 0 , latency, asymptomatic, however, the patient complained of 'heaviness'; stage I, spontaneously reversible, mild; stage II, spontaneously irreversible, moderate; and stage III, lymphostatic elephantiasis, severe. Medical records lacking 3 or more information were excluded.

For the quantitative variables [age, body mass index (BMI)], time evolution of disease, chemotherapy, radiotherapy and number of sessions) the descriptive analysis was expressed as mean and standard deviation (SD). The qualitative variables (gender, alcoholism, smoking, medical diagnosis, neck dissection, complaints, cutaneous sensibility, scars, lymphedema, pain, physical therapy modalities and outcome) were verified using the test of equality of two proportions. Paired student's t-test was used for comparison between pain before (initial VAS) and after treatment (final VAS); Wilcoxon test was used to compare the initial and final measurements. All tests were performed at a significance level of $5 \%(p \leq 0.05)$.

\section{RESULTS}

Of the 32 medical records, $9.4 \%(n=3)$ were excluded due to incomplete information, remaining 29 patients in the study. Table 1 shows data relating to gender, age, BMI, alcoholism, smoking, diagnosis, medical treatment and complications. On average, the time evolution of disease from diagnosis until the end of the medical treatment and the beginning of the physical therapy was $55.4 \pm$ 27.9 months, ranging from 24 to 120 months.

Moderate lymphedema was the most prevalent (51.7\%; $\mathrm{n}=15)$, followed by mild lymphedema $(31 \%$; $n=9)$, with no significant difference between them $(\mathrm{p}=0.110)$, and severe lymphedema $(6.9 \% ; n=2 ;<0.001)$, which occurred in the eyelids affecting locomotion. No lymphedema was observed in $10.3 \%(n=3 ;<0.001)$ of patients. Before treatment, $82.8 \%(n=24)$ of the patients reported pain, with an average of $7.1 \pm 2.4$ VAS and after the treatment, $62.1 \%(n=18 ; p=0.078)$ with an average of $3.5 \pm 1.4(<0.001)$.

Table 1: Characterization of patients according to gender, age, BMI, smoking, alcoholism, diagnosis, medical treatment and major complaints

\begin{tabular}{|c|c|c|c|c|}
\hline & & $n$ & $\%$ & $p$-value \\
\hline \multirow[t]{2}{*}{ Gender } & Female & 4 & 13.8 & $<0.001$ \\
\hline & Male & 25 & 86.2 & \\
\hline Age (years) & $54.1 \pm 12.6$ & & & \\
\hline BMI $\left(\mathrm{kg} / \mathrm{m}^{2}\right)$ & $22.2 \pm 3.4(14.89-29)$ & & & \\
\hline \multirow[t]{2}{*}{ Smoker } & Yes & 17 & 58.6 & 0.189 \\
\hline & No & 12 & 41.4 & \\
\hline \multirow[t]{2}{*}{ Alcoholic } & Yes & 13 & 44.8 & 0.431 \\
\hline & No & 16 & 55.2 & \\
\hline \multirow[t]{7}{*}{ Cancer } & Oral cavity & 12 & 41.4 & Ref. \\
\hline & Larynx & 8 & 27.6 & 0.269 \\
\hline & Farynx & 6 & 20.7 & 0.089 \\
\hline & Lacrimal canaliculus & 1 & 3.4 & 0.001 \\
\hline & Mandible & 2 & 6.9 & 0.002 \\
\hline & Thyroid & 2 & 6.9 & 0.002 \\
\hline & Parotid & 1 & 3.4 & 0.001 \\
\hline \multirow[t]{5}{*}{$\begin{array}{l}\text { Cervical } \\
\text { dissection }\end{array}$} & Radical unilateral & 10 & 34.5 & $\begin{array}{l}\text { Ref./ } \\
\text { NS }\end{array}$ \\
\hline & Radical bilateral & 10 & 34.5 & \\
\hline & Modified unilateral & 2 & 6.9 & 0.010 \\
\hline & Modified bilateral & 1 & 3.4 & 0.003 \\
\hline & No dissection & 6 & 20.7 & 0.240 \\
\hline \multirow[t]{2}{*}{ Chemotherapy } & Yes & 15 & 51.7 & 0.793 \\
\hline & No & 14 & 48.3 & \\
\hline \multirow[t]{2}{*}{ Radiotherapy } & Yes & 25 & 86.2 & $<0.001$ \\
\hline & No & 4 & 13.8 & \\
\hline \multirow[t]{8}{*}{ Complaints } & Lymphedema & 26 & 89.7 & Ref. \\
\hline & Pain & 24 & 82.8 & 0.152 \\
\hline & ROM limitation & 5 & 17.2 & $<0.001$ \\
\hline & Paresthesia & 5 & 17.2 & $<0.001$ \\
\hline & Muscle weakness & 2 & 6.9 & $<0.001$ \\
\hline & Trismus & 1 & 3.4 & $<0.001$ \\
\hline & Mucositis & 1 & 3.4 & $<0.001$ \\
\hline & Facial paralysis & 1 & 3.4 & $<0.001$ \\
\hline
\end{tabular}

Values of $p<0.05$ were considered statistically significant; the test of equality of two proportions; Ref.: Reference value in comparison with the other items; NS: No significant difference 
Table 2: Distribution of physical examination data related to pain, scarring and cutaneous sensibility

\begin{tabular}{|c|c|c|c|c|c|c|}
\hline \multirow{2}{*}{$\begin{array}{l}\text { Physical } \\
\text { examination }\end{array}$} & & \multicolumn{2}{|c|}{ Initial } & \multicolumn{2}{|c|}{ Final } & \multirow[b]{2}{*}{$p$-value } \\
\hline & & $n$ & $\%$ & $n$ & $\%$ & \\
\hline \multirow[t]{2}{*}{ Pain } & Absent & 5 & 17.2 & 11 & 37.9 & 0.078 \\
\hline & Present & 24 & 82.8 & 18 & 62.1 & \\
\hline \multirow[t]{6}{*}{ Scars } & Normotrophic & 19 & 65.5 & 25 & 86.2 & 0.066 \\
\hline & Adherence & 8 & 27.6 & 4 & 13.8 & 0.195 \\
\hline & Fibrosis & 5 & 17.2 & 4 & 13.8 & 0.717 \\
\hline & $\begin{array}{l}\text { Hypertrophic/ } \\
\text { keloid }\end{array}$ & 3 & 10.3 & 1 & 3.4 & 0.300 \\
\hline & Dehiscence & 2 & 6.9 & 0 & 0.0 & 0.150 \\
\hline & Absent & 1 & 3.4 & 1 & 3.4 & 1.000 \\
\hline \multirow{5}{*}{$\begin{array}{l}\text { Cutaneous } \\
\text { sensibility }\end{array}$} & Hypoesthesia & 15 & 51.7 & 12 & 41.4 & 0.430 \\
\hline & Normoesthesia & 7 & 24.1 & 12 & 41.4 & 0.162 \\
\hline & Anesthesia & 9 & 31 & 3 & 10.3 & 0.052 \\
\hline & Hyperesthesia & 5 & 17.2 & 1 & 3.4 & 0.085 \\
\hline & Not informed & 4 & 13.8 & 4 & 13.8 & 1.000 \\
\hline
\end{tabular}

Values of $p<0.05$ were considered statistically significant; Test of equality of two proportions

Table 2 shows the distribution of pain, scarring and cutaneous sensibility before and after the physical therapy.

For the analysis of lymphedema, measurements were compared before and after treatment, but only in 20 medical records it had complete information which was used for this variable. There was a significant reduction of the eleven measurements as shown in Graph 1.

The physical therapy modalities used in the treatment and their subtypes are shown in Table 3.

The average number of sessions was $19.3 \pm 14.5$. The main outcome reported was the discharge from physiotherapy $(65.5 \% ; n=19 ;<0.001)$, followed by abandonment of treatment $(10.3 \% ; \mathrm{n}=3)$, absences due to disease

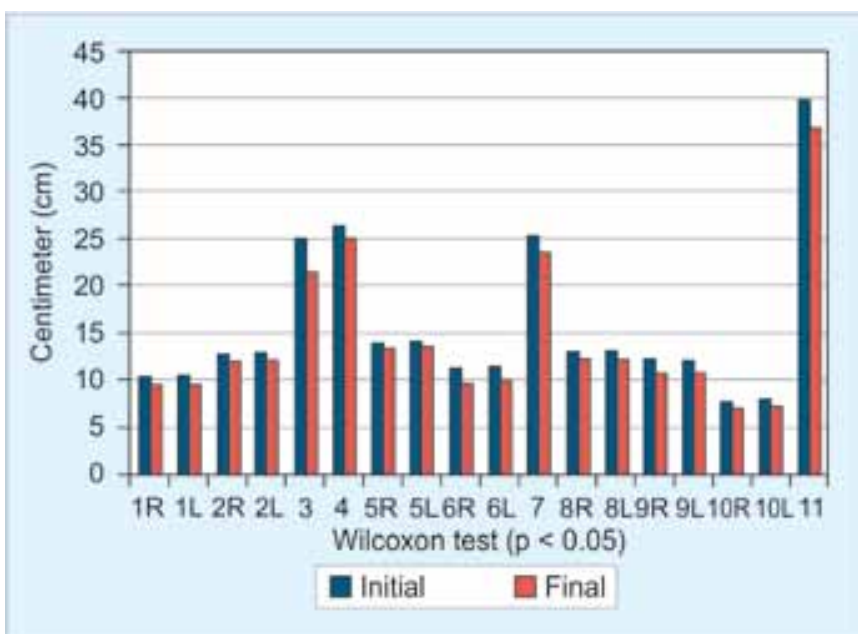

Graph 1: Facial and cervical measurements before and after physical therapy of 20 patients containing 11 measurements according to Tacani et al $(2010)^{16}$ (Wilcoxon test with statistically significant difference $(p<0.05)$ for the 11 measurements assessed)
Table 3: Distribution of physical therapy modalities used in the treatment

\begin{tabular}{|c|c|c|c|c|c|c|}
\hline \multirow[b]{2}{*}{ Modality } & \multirow[b]{2}{*}{ Description } & \multicolumn{2}{|c|}{ Yes } & \multicolumn{2}{|c|}{ No } & \multirow[b]{2}{*}{$p$-value } \\
\hline & & $n$ & $\%$ & $n$ & $\%$ & \\
\hline \multirow[t]{5}{*}{$\begin{array}{l}\text { Manual } \\
\text { therapy }\end{array}$} & $\begin{array}{l}\text { Manual } \\
\text { lymphatic } \\
\text { drainage }\end{array}$ & 26 & 89.7 & 3 & 1.3 & $<0.001$ \\
\hline & $\begin{array}{l}\text { MLD physio- } \\
\text { logical }\end{array}$ & 3 & 10.3 & 23 & 79.3 & $<0.001$ \\
\hline & MLD strategic & 23 & 7.3 & 3 & 10.3 & $<0.001$ \\
\hline & Pompage & 16 & 55.2 & 13 & 44.8 & 0.431 \\
\hline & Classic massage & 24 & 82.8 & 5 & 17.2 & $<0.001$ \\
\hline \multirow{4}{*}{$\begin{array}{l}\text { Physical } \\
\text { agents }\end{array}$} & TENS & 15 & 51.7 & 14 & 48.3 & 0.793 \\
\hline & $\begin{array}{l}\text { Mechanical } \\
\text { massage } \\
\text { therapy }\end{array}$ & 11 & 37.9 & 18 & 62.1 & 0.066 \\
\hline & $\begin{array}{l}\text { Ozone high } \\
\text { frequency }\end{array}$ & 5 & 17.2 & 24 & 82.8 & 0.001 \\
\hline & $\begin{array}{l}\text { Low level laser } \\
\text { therapy (LLLT) }\end{array}$ & 2 & 6.9 & 27 & 93.1 & 0.001 \\
\hline \multirow{4}{*}{$\begin{array}{l}\text { Therapeutic } \\
\text { exercises }\end{array}$} & Stretching & 23 & 79.3 & 6 & 20.7 & 0.001 \\
\hline & Facial & 18 & 62.1 & 11 & 37.9 & 0.066 \\
\hline & $\begin{array}{l}\text { Muscle } \\
\text { strengthening }\end{array}$ & 17 & 58.6 & 12 & 41.4 & 0.189 \\
\hline & ROM & 15 & 51.7 & 14 & 48.3 & 0.793 \\
\hline $\begin{array}{l}\text { Compressive } \\
\text { therapy }\end{array}$ & $\begin{array}{l}\text { Elastic facial } \\
\text { bandage }\end{array}$ & 14 & 48.3 & 15 & 51.7 & 0.793 \\
\hline $\begin{array}{l}\text { Patient } \\
\text { education }\end{array}$ & $\begin{array}{l}\text { Self-massage } \\
\text { and home- } \\
\text { exercises }\end{array}$ & 29 & 100 & 0 & 0 & $<0.001$ \\
\hline
\end{tabular}

Values of $p<0.05$ were considered statistically significant; test for equality of two proportions; TENS: Transcutaneous electrical nerve stimulation; ROM: Range of motion

complications $(6.9 \% ; \mathrm{n}=2)$, patients still undergoing treatment $(6.9 \% ; n=2)$, death $(6.9 \% ; n=2)$, and referral for rehabilitation of associated neurological disease (Stroke $3.4 \% ; n=1)$.

\section{DISCUSSION}

In the tested population, most of the patients were males $(80 \%)$, with an average age of $54.2 \pm 12$ years, $65 \%$ smokers and $60 \%$ alcoholics, as pointed out by some other authors who described a higher incidence of malignant tumors of head and neck cancer in men associated with alcohol and smoking, especially after 50 years of age. ${ }^{3,6,7,10,16,18-20}$ Büntzel et al $(2007)^{11}$ conducted a prospective study with 851 patients who presented late complications after head and neck cancer treatment (xerostomia-89.9\%, dysphagia-78.8\% and lymphedema $-48.4 \%$ ) and found a higher prevalence in males $(\mathrm{n}=717 ; 84.25 \%)$ with a mean age of 61.13 years $(21-85$ years), as well as Deng et al (2012) ${ }^{10}$ who analyzed 81 patients, among them 58 (71.6\%) were males, mean ages of 59.55 years, $55(67.9 \%)$ were smokers, $48(59.3 \%)$ were 
nonalcoholics. These values were similar to those found in the present study.

For BMI, an average of $22.1 \pm 3.6 \mathrm{~kg} / \mathrm{m}^{2}$ was observed and classified as normal. ${ }^{21}$ However, $6.9 \%$ of patients were severely underweight (BMI 14.89 and $\left.14.94 \mathrm{~kg} / \mathrm{m}^{2}\right){ }_{,}^{21}$ a common condition considered for those undergoing a cancer treatment as they lose appetite or desire to eat, resulting in lower food intake, weight loss, depletion of lean and adipose tissue, and consequently, cachexia. ${ }^{22}$

Most of the tumors found in that sample were located in the oral cavity, which corroborates the findings of Agra et al $(2003)^{3}$ who found those tumors in $49.2 \%(n=124)$ of patients, but the results differ from the international studies who described a higher incidence in the oropharynx. 6,10

Regarding treatment, it was observed that approximately $70 \%(n=20)$ of the patients underwent radical neck dissection (unilateral or bilateral) and 86.2\% were subjected to radiation, which may cause complications and acute and late functional limitations. ${ }^{5,23}$

Among the complications observed in this study, lymphedema was the most prevalent, affecting $89.7 \%$ of the patients while pain was reported by $82.8 \%$, with no significant differences ( $p=0.152$ ). The European literature suggests that the incidence of lymphedema is 12 to $54 \%{ }^{11,24,25}$ and, in the USA, it is $75.3 \%{ }^{10}$ The development of lymphedema seems to be more related to the types of neck dissection combined with radiation, which leads to a wide resection of the lymphatic pathways caused by radiodermatitis, harming the function of the lymphatic system. A study reported a higher prevalence of lymphedema when the surgical treatment was associated with radiotherapy, ${ }^{10}$ as also observed in our study, but others also related its development with radiotherapy or radiochemotherapy. ${ }^{6,11}$

Pain and its influence on the patients' life were recently addressed by Rogers et al $(2012)^{26}$ in their prospective study involving mouth and oropharyngeal cancer. The authors have identified 38\% (67/177) of patients who complained of pain; 'pain in the head and neck' in $18 \%$ (32/177) of cases; 'pain elsewhere' in 10\% (17/177); and in other locations in 24\% (43/177). Moreover, pain can have various origins and it was cited by $35 \%$ of the patients due to tumor recurrence and by $30 \%$ due to the treatment itself. ${ }^{7}$ Pain and shoulder dysfunction after surgery have been correlated from 18 to $77 \%$ in patients undergoing modified radical neck dissection and from 29 to $39 \%$ after selective dissection. ${ }^{27}$ In the present study, there was a high prevalence of pain $(82.8 \%)$ when compared to the aforementioned studies, which could be related to the most prevalent treatments used (radical neck dissection and radiotherapy). ${ }^{7}$ Pain can be nociceptive and neuropathic in $37.5 \%$ of patients and myofascial in $13 \%,{ }^{7}$ as it can be associated with the functional disability of the shoulder and neck, depending on the structures removed and the amount of fibrosis, which explains the prevalence of initial pain in more than $80 \%$ of the sample.

Moreover, pain can be closely related to shoulder dysfunction after neck dissection, preserving $(67 \%)^{15}$ or not $(20-60 \%)^{12}$ the accessory nerve and causing late microtrauma, such as a mechanical traction because the nerve is also less protected by the soft tissues, leading to poor vascularization as well as tension and myofascial pain of the trapezius, levator scapulae and rhomboid muscles. The entire condition can limit the ROM and weaken the muscles, also observed in our sample.

Considering the scar evolution, there was a prevalence of normotrophic scars before the physiotherapeutic treatment, with a higher percentage being observed (65.586.2\%) after treatment. Probably, the scar complications previously observed have improved with treatment, decreasing the percentages in the end, such as adhesions, fibrosis, hypertrophy, keloid (55.1-31\%) and dehiscence $(6.9-0 \%)$ and increasing the percentage of normotrophic scars (65.5-86.2\%). Schiefke et al (2009) ${ }^{24}$ observed changes in the scar length, complexion and texture as well as some limitation of skin movements in 25 patients who underwent selective neck dissection (levels I-III). Menezes et al (2006), ${ }^{4}$ observed that suture dehiscence was present in $5.8 \%$. Cutaneous sensibility changes were identified by Schiefke et al (2009) ${ }^{24}$ with significant reduction in both epicritic and protophatic sensitivity scores observed in the neck (peri-scar zone), similar to the findings in our study involving more than $82 \%$ of the patients, $51.7 \%$ with hypoesthesia and $31 \%$ with anesthesia.

Complications regarding wound healing and cutaneous sensibility are being treated with the use of manual, mechanical, and phototherapeutic modalities, depending on their evolution, as observed in this study, in which low level laser therapy (LLLT) was applied due its healing action on scars, exerting significant effects on mitochondria, fibroblasts and the immune process, ${ }^{28}$ while the ozone high frequency was used due to its bactericidal effects. ${ }^{29}$ In addition, the LLLT has also been widely used in the treatment of oral mucositis, according to Gautam et al (2012), ${ }^{28}$ who observed a significant reduction in the incidence of severe mucositis, pain, dysphagia and use of opioid analgesics in the group of 221 patients treated with LLLT and undergoing chemotherapy.

Mechanical massage therapy is another modality used for the stimulation of cutaneous receptors, reduction of cutaneous stiffness and cicatricial fibrosis. It was used in $37.9 \%$ ( $n=11)$ of patients in this sample and may have contributed to the increase in normotrophy and normoesthesia as shown in Figure 1. 

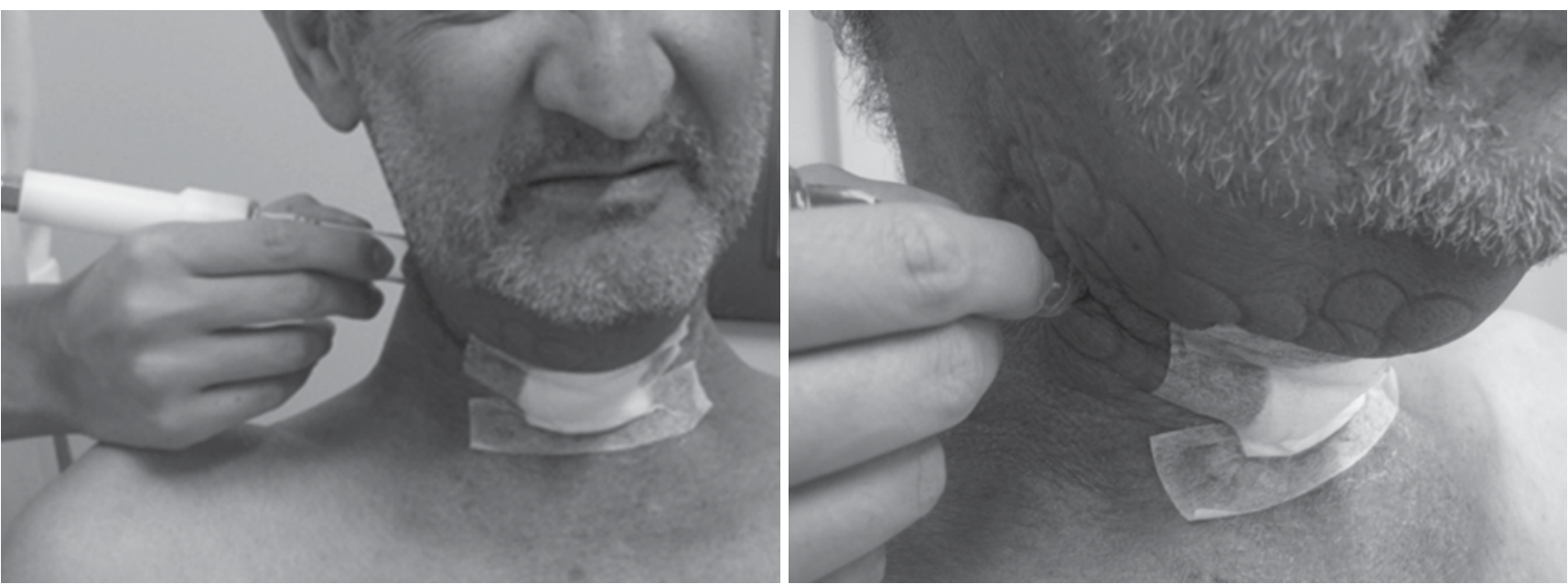

Fig. 1: Application of mechanical massage therapy to reduce adherences and scarring (fibrosis)

Bourgeois et al $(2008)^{30}$ observed that 12 women with breast cancer and post-radiation cutaneous fibrosis (from 6 to 16 months after) obtained significant improvement of erythema, pain, itching and scarring adhesions after 12 sessions of endermologie ( $\mathrm{LPG}^{\circledR}$ technique), a type of mechanical massage made by motorized machines with rollers and negative pressure, similar to the machine used in our physical therapy service.

The radiotherapy-induced fibrosis is characterized by a disorganized extracellular matrix, an excessive production of myofibroblasts, and a major deregulation in collagen synthesis, increasing the formation of fibrotic tissues and causing contracture and lesions in the lymph vessels. ${ }^{31,32}$ It may lead to head and neck lymphedema, which can coexist with fibrosis and contribute to tissue hardening, generating different sensations, such as tightness, stiffness, tension, pain and limitation of the neck movements, throat tightness, swallowing disorders, speaking, feeding and breathing. ${ }^{18,19}$

The treatment of lymphedema is based on the complex decongestive therapy (CDT) $)^{9,17,18}$ which includes manual lymphatic drainage, skin care and compressive therapy. In the present study, physiological or strategic lymphatic drainage was used, with the later being the most prevalent, as it is possible to adapt the stimulation of lymphatic channels seeking healthy regions due to neck dissection, fibrosis, and tissue adhesions that may affect the lymphatic function. Moreover, the combination of compression therapy with exercises contributes for a quicker removal of excess fluid and interstitial macromolecules, increasing the transport capacity of the lymphatic system and reducing the formation lymphatic fibrosis due to the high protein content of lymphedema ${ }^{9,17,18}$ corroborating the significant reduction of lymphedema observed in measurements (Graph 1). Piso et al (2001) ${ }^{20}$ conducted a study in 11 patients with secondary lymphedema after head and neck surgery. They were submitted to
10 sessions of MLD combined with the use of compressive mask. The results also showed a significant reduction of lymphedema. However, the average number of sessions was higher $(19.3 \pm 14.5)$ in the sample of this study, probably due to the more fibrous characteristics of the present data, justifying the longer period for the reduction and the use of suction-assisted massage therapy to soften those tissues. In addition, these authors ${ }^{20}$ observed the presence of tension-type headache pain caused by edema (VAS = 4.4), similar to this study, in which the average has reduced significantly from $7.1 \pm 2.4$ to $3.5 \pm$ 1.4, despite the nonsignificant reduction in the number of patients with presence of pain before $(82.8 \% ; n=24)$ and after $(62.1 \% ; n=18 ; \mathrm{p}=0.078) \mathrm{CDT}$.

Pain reduction may also be related to other procedures that are used to promote analgesia, such as pompage $(55.2 \%)$, classical massage $(82.8 \%)$, exercises $(79.1 \%)$ and TENS (51.7\%). ${ }^{7,12,15}$ The manual techniques have been identified in the literature as being beneficial to cancer patients as long as they are properly adapted to them and can help reduce some symptoms, such as pain, fatigue, stress, anxiety, nausea and depression. ${ }^{33}$ Marszalek et al $(2009)^{34}$ evaluated the influence of myofascial release techniques in esophageal pressure and cervical and scapular tension in 40 patients, who underwent total laryngectomy ( $n=40 / 100 \%)$, neck dissection $(n=35 / 87.5 \%)$, and radiotherapy ( $n=38 / 95 \%$ ) after 9 months to 13 years of treatment. Esophageal pressure was measured before and after a single session of physiotherapy, which consists of the use of myofascial release techniques in the upper body, shoulders, arms, neck and head. These authors observed a significant reduction in pressure from 37.9 to $26.6 \mathrm{~mm} \mathrm{Hg}$, suggesting that those manual techniques can help the patient's speech and swallowing.

Transcutaneous electrical nerve stimulation (TENS) has been widely used as an analgesic modality since $1967 . .^{35}$ It can significantly reduce the use of opioid 
medication, pain, nausea and itching, which justifies its use in clinical practice to control the postoperative pain and pain related to shoulder dysfunction in patients undergoing neck dissection. However, there is a lack of specific studies that can really analyze the use of such parameters in this population. $7,35,36$

According to the theory of Marszalek et al (2009) ${ }^{34}$, the patients who undergo total laryngectomy can have their superficial and deep muscle groups removed, leaving extensive scarring, which limits the ROM of cervical extension and weakening the neck flexors due to the increased tension of the antagonist muscles. Consequently, can occur muscular compensation with increased tone of trapezoid, erector spine and levator scapulae, causing an imbalance in the muscles of the neck and shoulders?

To aggravate this condition, emotion factors caused by anxiety, stress, and surgery related to the cancer diagnosis can intensify the tension in these muscles. This static and dynamic overload makes rehabilitation difficult and can impair the motor function of these patients. ${ }^{15,34}$ The use of manual techniques to provide relief from tension and muscle stiffness combined with fibrosis, improves skin and muscle blood flow, reduces pain and anxiety ${ }^{1,7}$ favoring the use of these techniques followed by reeducation exercises aiming to initially increase ROM, flexibility and mobility and muscle strength, so that the functional activities can be performed. ${ }^{12,15}$

Most patients of the present study, performed stretching (79.3\%), facial (62.1\%), muscle strengthening (58.6\%) and ROM (51.7\%) exercises, which may also have contributed for the reduction of pain, lymphedema, ROM limitation, and muscle weakness. ${ }^{1,7,12,15}$

McNeely et al (2008) ${ }^{12}$ verified improvement of pain, dysfunction, muscle strength and resistance of the upper limb girdle after a 12 weeks program of therapeutic exercises on postoperative surgery of head and neck cancer. The standardize training group performed ROM, stretching, posture and strengthening exercises and in the progressive resistance training group, the strengthening exercises were modified. The 12-week therapy period was similar to the data found in this study, as it obtained an average of 19.3 sessions, once or twice a week, according to our routine medical care service, with $65.5 \%$ of discharges from the treatment, indicating that most patients have evolved positively with the proposed therapy.

One of the limitations found in the present study refers to the lack of information within the retrospective study design, since it was not possible to properly analyze and compare ROM and the muscular strength provided by the patients' medical records. Nevertheless, it was possible to demonstrate that the role of physiotherapy in patients submitted to surgical treatment associated with radiotherapy and chemotherapy can help the patients return to their daily activities sooner and relieve their symptoms.

\section{CONCLUSION}

Physical therapy in late post-treatment complications of head and neck cancer was effective in reducing pain and lymphedema, combining manual lymphatic drainage, TENS, mechanical massage therapy, stretching exercises and patient education, with an average of 19 sessions and discharge after treatment.

\section{REFERENCES}

1. Fialka-Moser V, Crevenna R, Korpan M, Quittan M. Cancer rehabilitation: particularly with aspects on physical impairments. J Rehabil Med 2003;35(4):153-162.

2. Payakachat N, Ounpraseuth S, Suen JY. Late complications and long-term quality of life for survivors ( $>5$ years) with history of head and neck cancer. Head Neck 2013;35(6):819-825.

3. Agra IM, Carvalho AL, Pontes E, et al. Postoperative complications after en bloc salvage surgery for head and neck cancer. Arch Otolaryngol Head Neck Surg 2003;129(12): 1317-1321.

4. Menezes MB, Bertelli AAT, Andrade SJC, et al. Complicações pós-operatórias em esvaziamentos cervicais. Rev Bras Cir Cab Pesc 2006;35(2):109-112.

5. Murphy BA, Gilbert J, Cmelak A, Ridner SH. Symptom control issues and supportive care of patients with head and neck cancers. Clin Adv Hematol Oncol 2007;5(10):807-822.

6. Deng J, Ridner SH, Murphy BA, Dietrich MS. Preliminary development of a lymphedema symptom assessment scale for patients with head and neck cancer. Support Care Cancer 2012;20(8):1911-1918.

7. Mozzini CB, Schuster RC, Mozzini AR. O esvaziamento cervical e o papel da fisioterapia na sua reabilitação. Rev Bras Cancerol 2007;53(1):55-61.

8. Murphy BA, Gilbert J. Dysphagia in head and neck cancer patients treated with radiation: assessment, sequelae, and rehabilitation. Semin Radiat Oncol 2009;19(1):35-42.

9. Smith BG, Lewin J. Lymphedema management in head and neck cancer. Curr Opin Otolaryngol Head Neck Surg 2010;18(3):153-158.

10. Deng J, Ridner SH, Dietrich MS, et al. Prevalence of secondary lymphedema in patients with head and neck cancer. J Pain Symptom Manage 2012;43(2):244-252.

11. Büntzel J, Glatzel M, Mücke R, Micke O, Bruns F. Influence of amifosfatine on late radiation-toxicity in head and neck cancer: a follow-up study. Anticancer Res 2007;27(4A):1953-1956.

12. McNeely ML, Parliament MB, Seikaly H, et al. Effect of exercise on upper extremity pain and dysfunction in head and neck cancer survivors: a randomized controlled trial. Am Cancer Society 2008;113(1):214-222.

13. Pinfildi CE, Liebano RE, Hochman BS, et al. Effect of lowlevel laser therapy on mast cells in viability of the transverse rectus abdominis musculocutaneous flap. Photomed Laser Surg 2009;27(2):337-343.

14. Fialka-Moser V, Vinzenz K. Postoperative physical rehabilitation: therapeutic goals and procedures in head and neck cancer. Fortschr Med 1990;108(7):131-133. 
15. McGarvey AC, Chiarelli PE, Osmotherly PG, Hojjman GR. Physiotherapy for acessory nerve shoulder dysfunction following neck dissection surgery: a literature review. Head Neck 2011;33(2):274-280.

16. Tacani PM, Santos APR, Poscolere DD, Padilha QCSV, Amatu TKI, Montezello D, et al. Protocolo de avaliação de linfedema de cabeça e pescoço. Rev Bras Cir Cab Pesc 2010;39(2):126-130.

17. Executive Committee of International Society of Lymphology. The diagnosis and treatment of peripheral lymphedema. Consensus document of the International Society of Lymphology. Lymphology 2009;42(3):51-60.

18. Deng J, Ridner SH, Murphy BA. Lymphedema in patients with head and cancer. Oncol Nurs Forum 2011;38(1):E1-E10.

19. Deng J, Murphy BA, Dietrich MS, et al. Impact of secondary lymphedema after head and neck cancer treatment on symptoms, functional status, and quality of life. Head Neck 2013;35(7):1026-1035.

20. Piso DU, Eckardt A, Liebermann A, Gutenbrunner C, Schäfer P, Gehrke A. Early rehabilitation of head-neck edema after curative surgery for orofacial tumors. Am J Phys Med Rehabil 2001;80(4)261-269.

21. World Health Organization. Global Database on Body Mass Index. 2010. Available at: http://www.who.int/bmi/index. jsp?introPage=intro_3.html. Accessed on July 5, 2012.

22. Couch M, Lai V, Cannon T, et al. Cancer cachexia syndrome in head and neck cancer patients: Part I. diagnosis, impact on quality of life and survival, and treatment. Head Neck 2007;29(4):401-411.

23. Zimmermann T, Leonhardt H, Kersting S, AlbrechtS, Range U, Eckelt U. Reduction of postoperative lymphedema after oral tumor surgery with sodium selenite. Biol Trace Elem Res 2005;106(3):193-203.

24. Schiefke F, Akdemir M, Weber A, Akdemir D, Singer S, Frerich B. Function, postoperative morbidity, and quality of life after cervical sentinel node biopsy and after selective neck dissection. Head Neck 2009;31(4):503-512.

25. Dietz A, Rudat V, Nollert J, Helbig M, Vanselow B, Weidauer $\mathrm{H}$. Chronic laryngeal edema as a late reaction to radiochemotherapy. HNO 1998;46(8):708-711.
26. Rogers SN, Cleator AJ, Lowe D, Ghazali N. Identifying painrelated concerns in routine follow-up clinics following oral and oropharyngeal cancer. World J Clin Oncol 2012;3(8):116-125.

27. Bradley PJ, Ferlito A, Silver CE, et al. Neck treatment and shoulder morbidity: still a challenge. Head Neck 2011;33(7): 1060-1067.

28. Gautam AP, Fernandes DJ, Vidyasagar MS, Maiya AG, Vadhiraja BM. Low level laser therapy for concurrent chemoradiotherapy induced oral mucositis in head and neck cancer patients: a triple blinded randomized controlled trial. Radiother Oncol 2012;104(3):349-354.

29. Machado AFP,HochmanB, Tacani PM, Liebano RE,Ferreira LM. Medical devices registration by ANVISA (Agência Nacional de Vigilância Sanitária). Clinics 2011;66(6):1095-1096.

30. Bourgeois JF, Gourgou S, Kramar A, Lagarde JM, Guillot B. A randomized, prospective study using the LPGs technique in treating radiation-induced skin fibrosis: clinical and profilometric analysis. Skin Research and Technology 2008; 14(1):71-76.

31. Oppenheimer R, Finkel R, Brennan A. Treatment of radiationinduced fibrosis of the face with manual compression therapy. Ear Nose Throat J 2004;83(7):478-480.

32. Avraham T, Clavin NW, Daluvoy SV, et al. Fibrosis is a key inhibitor of lymphatic regeneration. Plast Reconstr Surg 2009; 124(2):438-450.

33. Collinge W, MacDonald G, Walton T. Massage in supportive cancer care. Semin Oncol Nurs 2012;28(1):45-54.

34. Marszalek S, Zebryk-Stopa A, Krasny J, Obrebowski A, Golusinsk W. Estimation of influence of myofascial release techniques on esophageal pressure in patients after total laryngectomy. Eur Arch Otorhinolaryngol 2009;266(8): 1305-1308.

35. Nizard J, Lefaucheur JP,Helbert M, deChauvigny E, NguyenJP. Non-invasive stimulation therapies for the treatment of refractory pain. Discov Med 2012;14(74):21-31.

36. Hamza MA, White PF, Ahmed HE, Ghoname EA. Effect of the frequency of transcutaneous electrical nerve stimulation on the postoperative opioid analgesic requirement and recovery profile. Anesthesiology 1999;91(5):1232-1238. 